\title{
Feasibility of Man-Portable Power Generation Systems
}

\author{
Earl C. Allen and Nelson Fumo* \\ Mechanical Engineering Department, The University of Texas at Tyler, Tyler, TX \\ Student: eallen13@patriots.uttyler.edu \\ Mentor:nfumo@uttyler.edu*
}

\begin{abstract}
Electric power is the most common source of power for many portable devices used in outdoor recreation, emergency scenarios, and military applications. Batteries that have limitations regarding power and energy are currently meeting the power demand for most of these devices. There is a search to use alternative power sources for portable energy needs. This search has mostly been researched particularly for the military to satisfy functions necessary for soldiers. However, any alternative that would provide electricity in an efficient and timely manner is useful in many applications beyond the military. The feasibility of man-portable power generation systems using thermal energy from any kind of fuels needs to be studied further, to understand if they are truly an option for situations where batteries are currently used. In this study, the feasibility of fueled power systems is investigated. Commercially available small power systems show that they are not small enough to satisfy the definition of man-portable power system. However, power systems working on an internal combustion engine show to be a better option when compared to batteries and fuel cells
\end{abstract}

\section{KEYWORDS}

Fueled Power Generation; Man-portable Power; Power Density; Energy Density.

\section{INTRODUCTION}

There is a large need for power systems in today's age of technology, with all of the different devices that are reliant on some sort of electrical power source. ${ }^{1}$ In many cases, these devices are able to be connected to large-scale power systems or onto a power grid. However, there are many scenarios where connecting to a large-scale power system or onto a power grid is not possible. Because these scenarios exist, there is a need for portable power systems. These systems are designed to be used in scenarios such as, soldiers in combat, use in third world countries, and camping trips. Currently, there are already many systems that are small portable systems. The majority of these systems focus on the ability to charge cell phones. This is a very large market and is very important, but it does not mean that man-portable systems have to be restricted to this one particular function.

When someone is in a remote location and needs power, there are a couple of different types of systems that can be used. One example of this is an electric storage system, such as batteries or a person using a device to generate power. Electric storage systems are commonly used today for portable systems. The move to power generation systems for these applications needs to be further understood and further developed. ${ }^{2}$

All power systems have fuels that have certain characteristics. The key to creating small power systems is to be able to understand these characteristics and use those well in designing a portable power system. In order to maximize energy in as small of a system as possible, there has to be an understanding of energy density. There are two types of energy density specific energy, also known as gravimetric energy density, and volumetric energy density, generally referred to as energy density. Specific energy is simply energy per unit of mass, whereas volumetric energy density is energy per unit volume. ${ }^{3}$ These values are related to each other by density, and because of this one of these values may become more important in certain situations.

In order to create smaller scaled power systems there are some key concepts that need to be understood about fuels as well as the many options for fuels. There are a variety of fuel types and energy systems to use each of those fuel types. For the most part, these systems can be converted into small-scale systems in order to be able to be a portable system with the downside of producing less power. Fuels also have heating values. There are different measures for heating values, high heating value and low heating value. High heating value is the amount of heat that is released by a fuel when the temperature starts at $25^{\circ} \mathrm{C}$, is burned, then returns to $25^{\circ} \mathrm{C} .{ }^{4}$ Low heating value is the amount of heat released when the fuel starts at $25^{\circ} \mathrm{C}$, is burned, and then returns to $150^{\circ} \mathrm{C} .{ }^{4}$ These are each used in specific situations, high heating value is used when liquid water exists as a product at the end of the combustion process. Low heating value is used when water vapor exists as a product at the end of the combustion process. There are a wide variety of fuels that can be used in different systems, all of which fit in a few categories including fossil fuels, gaseous fuels, and renewable fuels. 
Another important aspect of power systems is the actual system itself. When the system is chosen it will help to limit the options for fuels that are usable with that system. The main value for being able to understand the usefulness of a system is the power density, which is the rate of energy flow measured in power per unit of volume. ${ }^{5}$ In this particular case though, there will be another limiting factor on systems and that is the ability to fit in the category of man-portable.

\section{Man-Portable Power}

To be able to understand what man-portable is, there first must be an understanding of portable. Portable is something that can be transported by people. ${ }^{6}$ The problem with this definition, when talking about power systems that need to be moved, is that by definition a portable system could take multiple people to move. For example, the Yamaha EF2000iSv2 Portable Inverter is a portable power system that weighs $44.1 \mathrm{lbs}$, but it may take multiple people to move it. ${ }^{7}$ There may be a person strong enough to move this portable system by themselves, but they will not be able to carry many other items with them at the same time. This would not be a viable option for someone who is in many scenarios such as someone backpacking or a soldier on a mission. Because of these scenarios, there is a need for man-portable power systems. Man-portable is defined by the Department of Defense as being a system that is less than 14 kilograms (31 pounds). The Department of Defense also describes man-portable power as, "equipment which can be carried by one man over long distance without serious degradation of the performance of normal duties". 8 While the Yamaha EF2000iSv2 Portable Inverter Generator may be a very useful power system in a scenario where a vehicle can be used, it would not be optimal in a scenario where just people would be required to transport it. With this definition of man-portable in mind, the previous example of the Yamaha EF2000iSv2 Portable Inverter Generator would be considered portable but would not fit the definition of man-portable. ${ }^{7}$

The definition of man-portable allows for an understanding that when creating a small power system, the greatest limitation is weight. Because the limiting factor based on that definition is weight, a design is not limited to the amount of power it can produce by definition. This means that there is a large need for understanding how to maximize power output base on weight. In a practical sense, though it is not defined based on the definition of man-portable, there is a need to keep within a reasonable volume. This means there needs to be a balance struck when choosing fuels. Just because there is a need to minimize weight does not mean that it may be necessarily reasonable to choose the fuel with the greatest specific energy. Based on the definition of man-portable the idea of what is reasonable for the amount of volume for a man-portable power system is left up to the engineer designing the system. The engineer may be helped in that decision by many constraints based on a specific application in which they are designing the system for. In the case of man-portable power, minimizing volume is still a priority. Since both of these are of huge importance for a man-portable system, there are a few fuels that would be considered the best fuels for man-portable applications. When discussing fuels later these will be very important values in selecting the best possible fuels for a man-portable system. ${ }^{7}$

\section{Ragone Plot}

When trying to understand energy storage systems it is helpful to be able to understand the options available and their characteristics through visuals. A well-known way to do this is through something called Ragone plots. A Ragone plot represents power density versus energy density of energy storage systems on a logarithmic scale. ${ }^{9}$ Both characteristics are very important when considering man-portable systems because they both are defined per unit of mass.

It is important to understand what specific energy and specific power mean in terms of production. If a system has a high specific energy, then it can produce energy for long periods of time. ${ }^{10}$ A system that has a high specific power would mean that the system can produce a lot of energy at a small interval of time for its weight. ${ }^{11}$ For instance, in the case of batteries, they have a high specific energy but they also have a relatively low specific power. Because of those properties, batteries are typically used to power systems that need to be powered for long periods of time, but they do not necessarily power systems that require a lot of power to run. It makes sense that it would be optimal to maximize both the specific power and specific energy for man-portable systems.

Most Ragone plots only show energy storage systems. However, the Ragone plot in Figure 1 also shows that combustion engines have more specific energy and more specific power than all the storage systems shown in the graph. This means that there is a very good potential that power systems have more specific power and more specific energy. ${ }^{5}$ This is a good reason to continue seeking out man-portable power generation systems as an option over man-portable energy storage systems. 


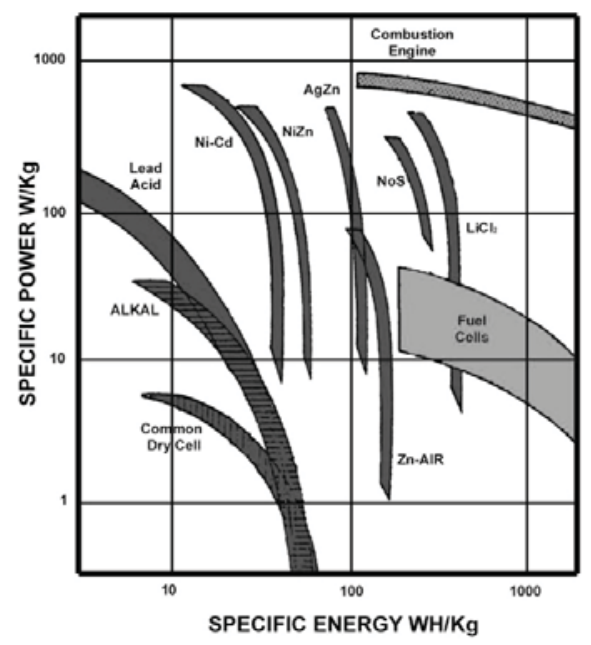

Figure 1. Example of a Ragone plot that includes many energy storage systems as well as combustion engines. ${ }^{12}$

\section{Fueled Power Systems}

There is a large amount of various types of small-scale power systems. Some of these small-scale power systems include: renewable energy systems, micro turbines, micro engines, Stirling engines, and Rankine Cycle systems. The reasons for using any of these systems should be weighed out in any design scenario. For man-portable the power system chosen should be usable no matter the environment. A man-portable power system should emphasize the ability for a lightweight design along with allowing for a small volume design. Preferably, a man-portable system would produce a relatively small amount of noise and produce a minimal amount of exhaust. ${ }^{13}$ If possible a man-portable power system would produce a low temperature profile as well, this would allow for it to be used for military applications. These many properties of any particular power system should be weighed out before choosing a particular way of producing man-portable power.

Renewable energy is a type of power source that is currently becoming very popular. For the purposes of this paper, Biomass will be considered separately even though it is considered renewable energy. This is because biomass can be interchanged with other fuel sources such as fossil fuels. Most renewable energy sources need a power system that is specific to that energy source. The best attribute of renewable energy, such as, wind, solar, and hydro power, is that it is virtually infinite. Wind and hydro power have not yet shown themselves to be a great source of portable power and most likely won't, due to the nature of them needing large amounts of fluid to be able to generate adequate power. Solar Energy, however, has shown itself to be a great source of portable power. There are already many portable systems that use solar energy and a battery to create energy on a small portable scale. Some of these, such as the Goal Zero Venture 30 Solar Recharging Kit, even fit the definition of man-portable because it weighs only 1.56 lbs. $^{14}$ Though the Goal Zero Venture 30 Solar Recharging Kit is specifically designed to recharge tablets and phones it would still be considered a man-portable power system. A great thing with the solar systems is that their power source is infinite, along with the fact that it does not need to be stored along with the power system. This limits the customer costs to simply buying the power system that they want and putting that system to use. It also keeps that person from having to carry some other form of fuel along with the power system they have creating extra weight during transportation. The limiting factor to a solar power system is the fact that the sun is not always accessible. There are many scenarios where a solar powered system would not be able to generate any power, and this severely limits its ability to be a great option for a man-portable power system. Scenarios such as natural disaster settings and night missions for soldiers make it necessary for other forms of power systems to be explored.

A form of small-scale engines used to produce power has become popular, this market is Portable Generators. Portable Generator Manufacturers' Association (PGMA) defines portable generators as engine driven power generators designed for portability. ${ }^{6}$ PGMA includes in their definition that generators designed to be transported via vehicle are not considered a portable generator. ${ }^{6}$ There is a large variety of portable generators that can be located online that include previously mention Yamaha EF2000iSv2 Portable Inverter Generator ${ }^{7}$ and another called the Pulsar 1200W 2-Stroke Generator. ${ }^{15}$ Both of these are portable power systems coming in at $44.1 \mathrm{lbs}$ and $37.5 \mathrm{lbs}$ respectively. There are many other portable generators that come in at similar weights; the problem is that both of these systems do not fit the definition of man-portable power systems. The fact that there is a large industry that has many products that have not met the man-portable definition would lead to a belief that micro engines may not be a good option for man-portable power. Recently, however, there has been a portable generator that meets the man-portable definition called the GenSmart 1000. The GenSmart 1000 weighs $12 \mathrm{lbs}$ and has a large amount of power output 
for its weight. ${ }^{16}$ The GenSmart 1000 also uses methanol as opposed to what most portable generators use, gasoline. ${ }^{16}$ This may mean that in order to create man-portable generators fuels may have to be studied more deeply. A downside to micro engines in general is that there must be some type of fuel to accompany the engine; consequently this fuel creates extra weight. Due to the extra fuel needing to be carried, the user also has to determine how much fuel they will need for their trip and find a way to carry that with them. This severally limits how long a micro engine could be used for a trip. The advantage of using micro engines is when the user needs energy it is easy to start up the micro engine and use just as much fuel as needed for that particular application. A further study of fuels specifically for micro engines could lead to a break through and allow micro engines to be a feasible idea for man-portable power.

A relatively new power system altogether is microturbines. ${ }^{17}$ When talking about micro turbines, the term micro does not refer to physical size but to the power capacity. Microturbines are currently built for distribution power purposes, which are primarily large-scale systems. ${ }^{18}$ This technology has a high specific power and high specific energy ${ }^{19}$, due to this , micro turbines could be an interesting option for portable power generation systems. Microturbines do not currently seem like a viable option for manportable power generation systems, because they have not yet proven that they can be made as small-scale systems.

Stirling engines are an interesting option for use, as a man-portable power system. There are many advantages to using Stirling engines, the main being that they are maintenance free and use fuel externally. ${ }^{20}$ Meaning that nearly any fuel could be used to power the system and, theoretically, the fuel used could be changed on a situational basis. Another major advantage to Stirling engines is that they are considered quiet machines. The fact that Stirling engines are quiet allows them to be a good option for use on military missions. It also makes Stirling engines a good option for camping if there were some need for the use of a power system overnight. The major downside to Stirling engines is their relatively low specific power compared to other power systems. ${ }^{19}$ This means that relative to other system there is not a possibility of getting a large amount of power in a man-portable system. Additionally, Stirling engines have a long start time which means if for some reason there was an urgent need for power then it would not be possible with a Stirling engine. ${ }^{19}$ When considering man-portable systems, the fact that Stirling engines have a low specific power makes it necessary to highly consider other options.

Fuels

After a type of power generation system has been chosen, the fuel to be used needs to be chosen. There are a variety of options available, but these options need to be understood in depth before making that decision. When talking about man-portable power systems, there will be some very specific properties that need to be discussed to make a good decision.

There are different types of fuels. The type of fuel used is very much dependent on the type of power generation system being used. For instance, renewable energies such as solar and wind, need specific power generation systems to generate power. Also, internal combustion engines are limited to types of fuels. However, external combustion systems can use nearly any type of fuel. Regardless it is good to have a proficient understanding of what type of fuel would be good to use in any specific power generation system.

Fuels are generally grouped into subsections of renewables and fossil fuels, each of these have even smaller subsections. For example, fossil fuels can be broken down into coals, petroleum, and gaseous fuels. In this case the fuels will instead be broken down into their states at room temperature such as gas, liquid, or solid. This is because, for man-portable power, it is crucial to know how the fuel would be carried as opposed to knowing the kinds of fuels.

Table 1 shows a list of common fuels. These fuels except for wood are fossil fuels; wood is considered a biomass fuel. This table gives some typical characteristics as well as their phase state and various properties relevant to this study. The properties shown in this table are high heating value, energy density, burn temperature, and the adiabatic flame temperature of the fuels. As a refresher, the high heating value is the amount of heat released, when a fuel starts at $25^{\circ} \mathrm{C}$ and then returns to $25^{\circ} \mathrm{C} .{ }^{4}$ Adiabatic flame temperature is the theoretical temperature that can be released if no heat is lost to the environment and no heat is added from the environment. ${ }^{21}$ These properties are relevant to determining what kind of fuel to use for a man-portable application. The main two properties that will be consistently seen with the same importance are the high heating value and energy density. These two values need a balance to be struck. As previously discussed, these values are related by density. Table 1 shows that there should not be a fuel chosen based on either the high heating value or energy density alone. A balance needs to be struck between both the weight and volume that is taken up for a fuel. For example, hydrogen has the highest heating value of any of the fuels listed but it also has a very low energy density. This means, while it may have a lot of energy for the amount of mass, it will take up a lot of space. With that being said, hydrogen is probably not a viable option as a fuel, for a man-portable system. 


\begin{tabular}{|c|c|c|c|c|c|}
\hline Fuel & State & $\begin{array}{l}\text { High Heating } \\
\text { Value } \\
\quad(\mathrm{kJ} / \mathrm{kg})\end{array}$ & $\begin{array}{l}\text { Energy Density } \\
(\mathrm{kJ} / \mathrm{L})\end{array}$ & $\begin{array}{l}\text { Burn } \\
\text { Temperature } \\
\qquad\left({ }^{\circ} \mathrm{C}\right)\end{array}$ & $\begin{array}{c}\text { Adiabatic Flame } \\
\text { Temperature } \\
\left({ }^{\circ} \mathrm{C}\right)\end{array}$ \\
\hline Anthracitic Coal & Solid & 27000 & 36450 & 600 & 2180 \\
\hline Bituminous Coal & Solid & 23250 & 0.026 & 454 & 2172 \\
\hline Diesel & Liquid & 44800 & 37184 & 210 & --- \\
\hline Ethane & Liquid & 51900 & 28246 & 515 & 1955 \\
\hline Ethanol & Liquid & 29700 & 23278 & 365 & 2082 \\
\hline Gasoline & Liquid & 47300 & 33867 & 246 & 2138 \\
\hline Hydrogen & Gas & 141790 & 0.00001 & 500 & 2254 \\
\hline Kerosene & Liquid & 46200 & 38346 & 295 & 2093 \\
\hline Lignite Coal & Solid & 16300 & 12015 & 526 & --- \\
\hline Methane & Liquid & 55530 & 23529 & 580 & 1963 \\
\hline Methanol & Liquid & 23000 & 17855 & 470 & 1949 \\
\hline Natural Gas & Gas & 71525 & 37300 & 580 & 1960 \\
\hline Propane & Gas & 50350 & 29449 & 455 & 1980 \\
\hline Wood & Solid & 17400 & 9000 & 300 & 1980 \\
\hline
\end{tabular}

Table 1. Properties of some well-known fuels.

The relationship between high heating value and energy density for the fuels given in Table 1 is shown in Figure 2 . Each fuel is plotted on the graph showing how it relates in terms of high heating value and energy density. Figure 2 shows that many fuels are similar in terms of their energy density to high heating value ratio. It can also be seen that the best fuel, in terms of energy density and high heating value, is Natural Gas. However, a large problem with a gas fuel is the way they need to be transported. Gas fuels are stored at high pressures this can be a safety issue for man-portable power systems. Also, the containers in which those gases are stored in must be very thick and bulky in order to hold those gases at high pressure. With the bulky containers, it would be worth looking at other options that would be able to produce a satisfactory amount of energy to the amount of weight including the container.

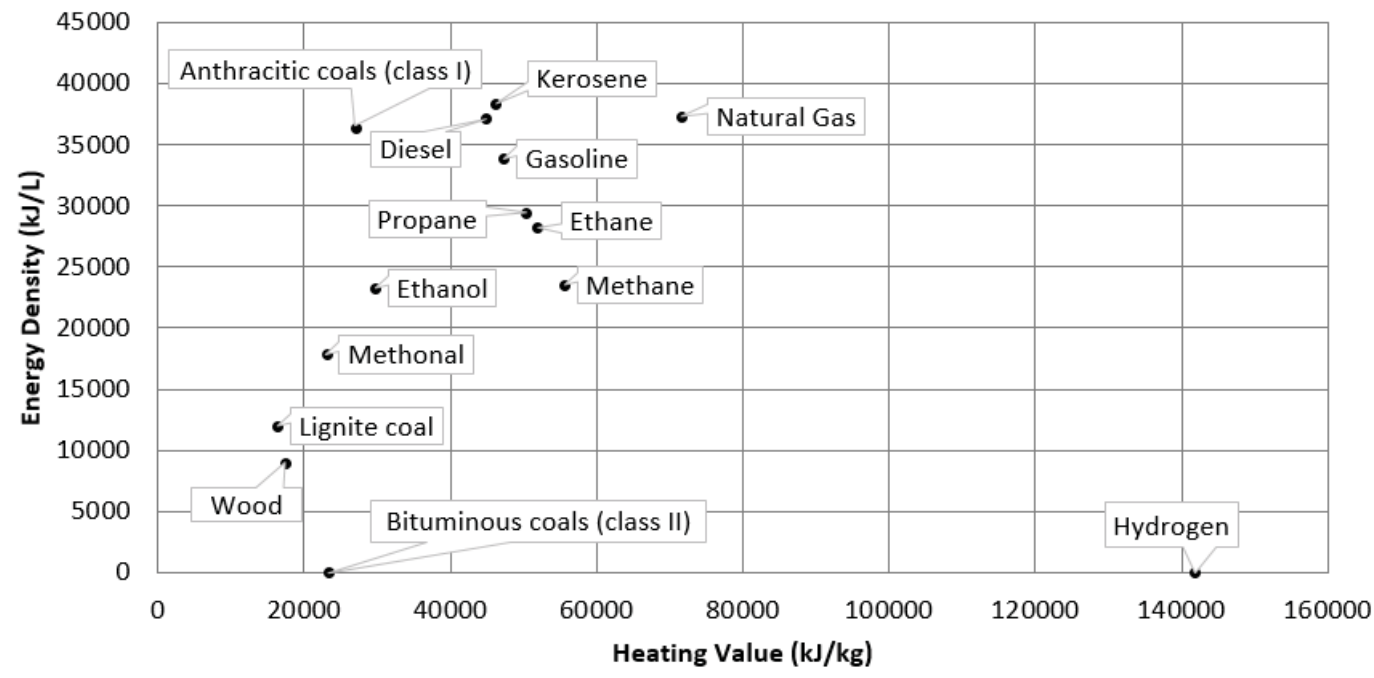

Figure 2. Fuels ratio of energy density and heating value.

Solids are another option for fuels. The main solid fuels that are used are coal and wood. Coals are generally used in large-scale facilities and are very hard to burn. As it can be seen from Table 1, the burn temperatures of the three types of coal are rather high, with the lowest burn temperature being $454^{\circ} \mathrm{C}$ for Lignite Coal. Coal would also be a rather difficult fuel to carry. The other solid option is wood. As shown in Figure 2, wood does not have a very good heating value or energy density, relative to other options. However, in the case of an external combustion engine, wood might be a good option as an alternative source of heat. This is because somebody who is in an area, particularly a campsite, could harvest wood for use as fuel to burn. Even though this is a feasible option, wood is still not a good selection when a choice is given. 
Liquids make up the majority of fuels. They are a very good option, because they are easy to carry at atmospheric pressure with a simple container. This is very crucial for man-portable situations. The two best options for liquid fuels in terms of their heating values and energy density are both kerosene and diesel fuel. Both kerosene and diesel are very close to each other in terms of heating value and energy density. Because they are comparable, it is worth noting that the burn temperature for kerosene is $295^{\circ} \mathrm{C}$ as compared to $210^{\circ} \mathrm{C}$ for diesel. That means that between the two fuels it is probably worth leaning towards diesel just because it is the easier fuel to burn. According to the Occupational Safety and Health Administration (OSHA), liquid fuels should be handled and transported in portable fuel containers. The portable containers should be metal, have tight closures (with screw or spring covers). ${ }^{22}$ They should also be equipped with spouts to allow pouring without spilling. If those fuel containers are used with portable generators, the containers should be directly attached to the generator frame to prevent static build-up and reduce risks of explosions.

\section{Current Portable Fuel Powered Systems}

Currently man-portable fuel powered systems do not have a large industry. However, there is a large industry for portable fuel powered systems, that being portable generators. This is a large industry that already exists and is good to be used to help understand what can be accomplished with man-portable fuel powered systems. Also, portable generators have man-portable fuel powered systems within them. Table 2 gives a list of 14 portable generators that are commercially available along with their specifications. Some of the specifications required basic calculations to be reached; those calculations were based on given information about the product. For example, volume was not given, but length, height, and width were, so those values were used to calculate volume.

One of the portable generators in Table 2 meets the definition of man-portable that was stated to be as a system that weighs less than 14 kilograms (31 pounds). This gives an idea of what is possible with man-portable fuel powered generators. This is a relatively limited view of what can be accomplished with man-portable fuel power systems because all the systems in Table 2 are internal combustion engines.

\begin{tabular}{|c|c|c|c|c|c|c|}
\hline Company & $\begin{array}{l}\text { Power } \\
\text { Output } \\
\text { (W) }\end{array}$ & $\begin{array}{l}\text { Weight } \\
\text { (kg) }\end{array}$ & $\begin{array}{l}\text { Specific } \\
\text { Power } \\
(\mathrm{W} / \mathrm{kg})\end{array}$ & $\begin{array}{l}\text { Volume } \\
\qquad\left(\mathrm{m}^{3}\right)\end{array}$ & $\begin{array}{c}\text { Gravimetric } \\
\text { Energy Density } \\
(\mathrm{Wh} / \mathrm{kg})\end{array}$ & Fuel \\
\hline Yamaha & 2000 & 20.0 & 100 & 0.0623 & 210 & Gasoline \\
\hline Pulsar & 1200 & 17.0 & 70 & 0.0368 & 225 & Dual Fuel \\
\hline Honda & 2000 & 20.7 & 97 & 0.0630 & 290 & Gasoline \\
\hline Sportsman & 4000 & 46.3 & 86 & 0.1284 & 432 & Propane \\
\hline $\begin{array}{l}\text { Champion } \\
\text { Power }\end{array}$ & 4000 & 48.6 & 82 & 0.1328 & 494 & Gasoline \\
\hline A-iPower & 4000 & 47.7 & 84 & 0.1189 & 503 & Gasoline \\
\hline Honda & 1000 & 13.0 & 77 & 0.0413 & 230 & Gasoline \\
\hline Honda & 3000 & 35.4 & 85 & 0.1155 & 212 & Gasoline \\
\hline Honda & 6500 & 81.3 & 80 & 0.2066 & 400 & Gasoline \\
\hline Honda & 3000 & 32.2 & 93 & 0.0857 & 437 & Gasoline \\
\hline $\begin{array}{l}\text { Briggs \& } \\
\text { Stratton }\end{array}$ & 8000 & 127.6 & 63 & 0.4406 & 353 & Gasoline \\
\hline Generac & 5500 & 83.0 & 66 & 0.3163 & 414 & Gasoline \\
\hline $\begin{array}{l}\text { Smarter } \\
\text { Tools }\end{array}$ & 6500 & 90.8 & 72 & 0.2794 & 413 & Dual Fuel \\
\hline Ryobi & 5500 & 88.1 & 62 & 0.2738 & 351 & Gasoline \\
\hline
\end{tabular}

Table 2. Characteristics of commercially available portable generators.

External combustion engines could be a design choice for portable generators as well as man-portable fuel powered systems. The main draw towards external combustion engines would be their versatility for fuels. They can use nearly any fuel that can be obtained. This is very useful in man-portable situations. If somebody is camping and they run out of the fuel they can use wood to help generate power. Another situation where this is beneficial is in a military setting. For example, if a soldier is on a mission and they run out of fuel, any other fuel available could be used, since a substitution for a different fuel will still produce the thermal energy needed by the power system. 
Figure 3 is built based on Table 2 and Figure 1 and is given to illustrate a relative comparison of different options for sources of power. Figure 1 shows that combustion engines have the potential to have both more specific power and more specific energy than current batteries and fuel cells. From Figure 1, regions 1, 2, and 3 in Figure 3 are shown for batteries, fuel cells, and combustion engines respectively. For comparison purposes, the current portable power generation systems were plotted on the logarithmic scale plot shown in Figure 3 and are represented by region 4. This shows that the current commercially available portable power generation systems are not yet meeting their theoretical capabilities. However, they are close to having more specific power than current batteries and they provide nearly as much specific energy as fuel cells. This means, that the current portable power generation systems already provide the best of both worlds, if there is a need for a lot of energy and a lot of power in a lightweight system. Based on Figure 1, since commercially available portable systems work with the same technology (thermodynamic cycles) as internal combustion engines, there is an expectation that portable systems will be able to provide more power and energy per unit of weight going forward in the future. This expectation is not being met, most likely because of their size. Power generation systems, based on internal combustion engines, have better efficiency for large capacity than a unit with less capacity. This decrease in efficiency has a negative effect on both the specific power and specific energy. Finding a way to create more efficient small scale fuel powered systems could allow for region 4 to get much closer to region 3 .

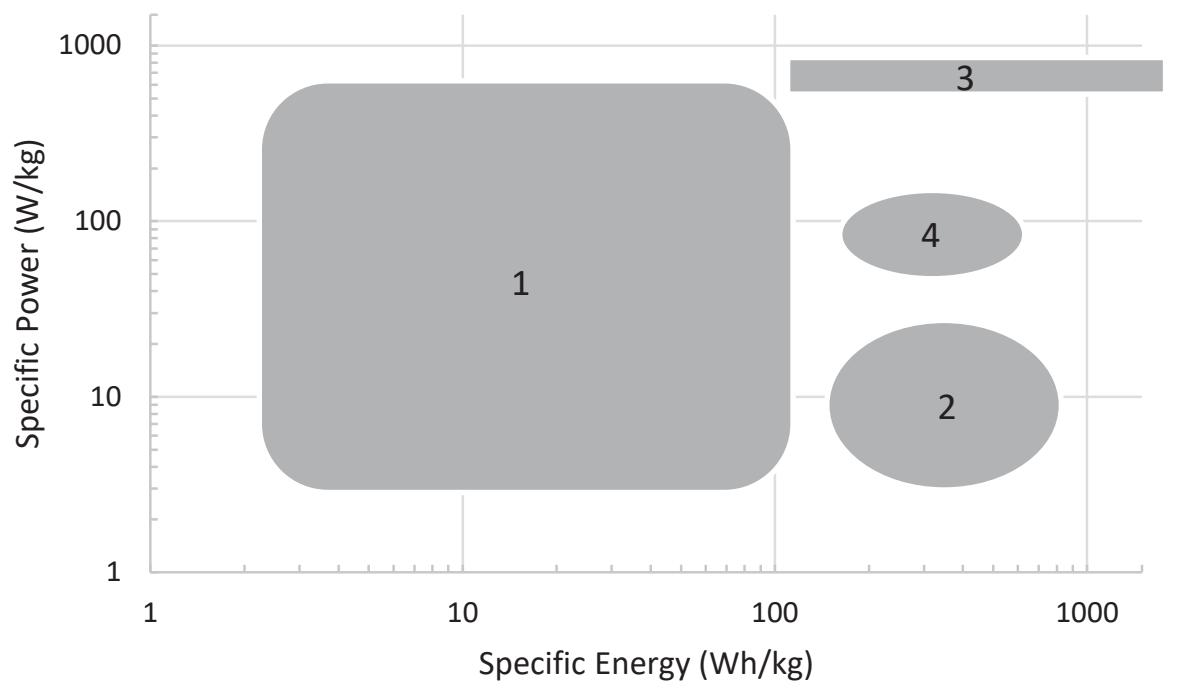

Figure 3. Ragone plot showing how commercially available Portable Power Systems compare to batteries and fuel cells and combustion engines. Number 1 refers to batteries, 2 refers to fuel cells, 3 refers to combustion engines, and 4 refers to current commercial portable fuel powered systems.

\section{Efficiency and Autonomy}

For the concept of a man-portable fuel power generator, the system is comprised of the engine, the fuel, and the container for the fuel. The volume, and consequently the weight, of the container is dependent on the amount (weight) of the fuel. Therefore, for the purposes of this study, the weight of the container has been set as 0.29 times the weight of the fuel. This value was obtained by weighing water in a stainless-steel tumbler, then getting the weight ratio of the empty container to the container full of water. The engine is a constant weight that by itself creates no energy. Since there is no energy created, when the power generation system is comprised of just an engine, the specific energy at that weight is zero. In the case of Figures $\mathbf{4}$ and $\mathbf{5}$ the specific weight of the engine was assumed to be $2.38 \mathrm{~kg}$. This weight was defined based on a need for $200 \mathrm{~W}$ (value assumed to be needed for radio communications in the military ${ }^{23}$ ) and a specific power of $84 \mathrm{~W} / \mathrm{kg}$ (assumed based on the average specific power of the portable power generation systems in Table 2). Once the fuel is introduced to the system there is specific energy. The total specific energy of the entire system is based on how much fuel is carried and therefore how much fuel the engine can use. That fuel is dependent on how much can be carried for the specific situation. This concept is shown in Figures 4, 5, and 6.

Figure 4 shows a comparison of how four different fuels affect the specific energy of a fuel power generation system. For this graph a fuel-to-electricity efficiency of the system was assumed to be $20 \%$. Also, a specific power of $84 \mathrm{~W} / \mathrm{kg}$ was assumed based on the average specific power of the portable power generation systems in Table 2 . The four fuels were chosen since propane, gasoline, and diesel can be found in portable power generation systems currently. Kerosene was chosen because from Figure 2 it can be noticed that it has a very good specific energy and specific power. As shown in Figure 4, these fuels provide a similar specific energy to the system when the same weight is carried out (at zero specific energy the weight is related to the weight of the system without any fuel). However, this figure also shows the importance of increasing the amount of fuel on the specific energy 
of the system. The first 50\% increase, in specific energy, happens within the first three kilograms of fuel added to the system. After the entire system reaches six kilograms the increase in specific energy per kilogram of fuel added is significantly less. In other words, the most significant change in specific energy increase come in the first mass of fuel and there is a much smaller impact of specific energy as more fuel is added to the system.

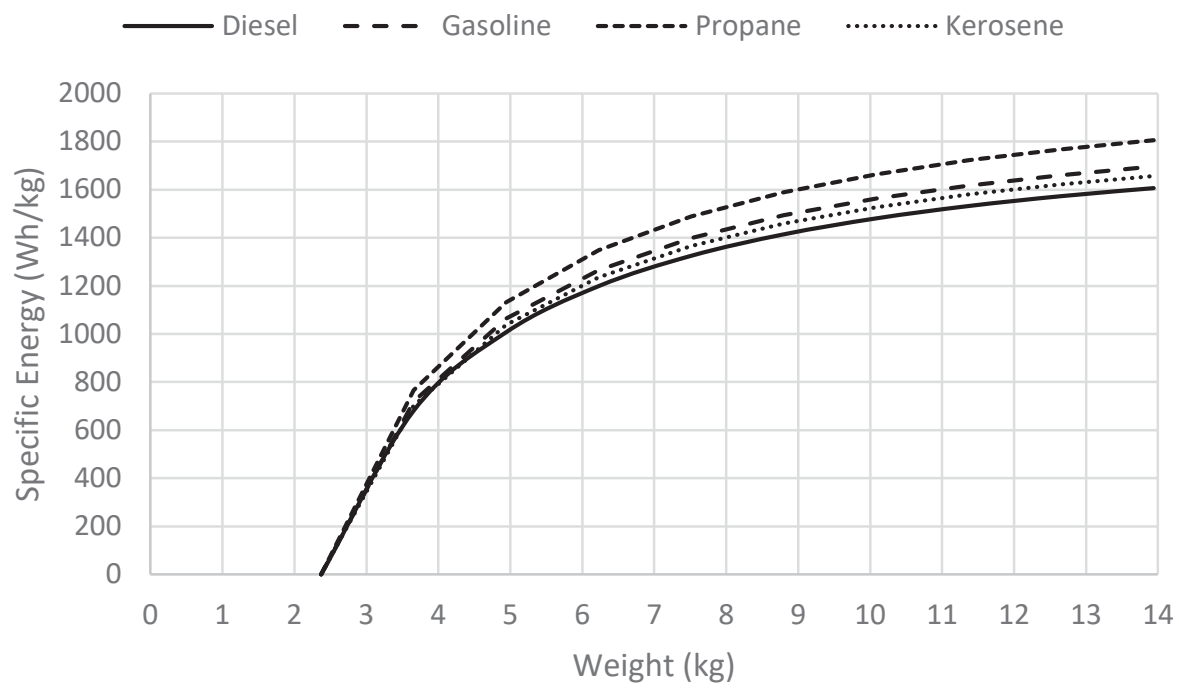

Figure 4. Comparison of four different fuels showing how much specific energy they can create with a standard engine based on the weight of the fuel. The specific power was set has $84 \mathrm{~W} / \mathrm{kg}$ and efficiency was set as $20 \%$.

Figure 5 illustrates the importance of the fuel-to-electricity efficiency of the system. This is based on the concept that the engine cannot create energy without fuel and the specific energy is dependent on the amount of fuel carried. This figure confirms the impact of the first kilograms of fuel carried for the system. As expected, the curves are proportional to each other throughout. This means that what was said to be true in Figure 4 previously, is true for all efficiencies.

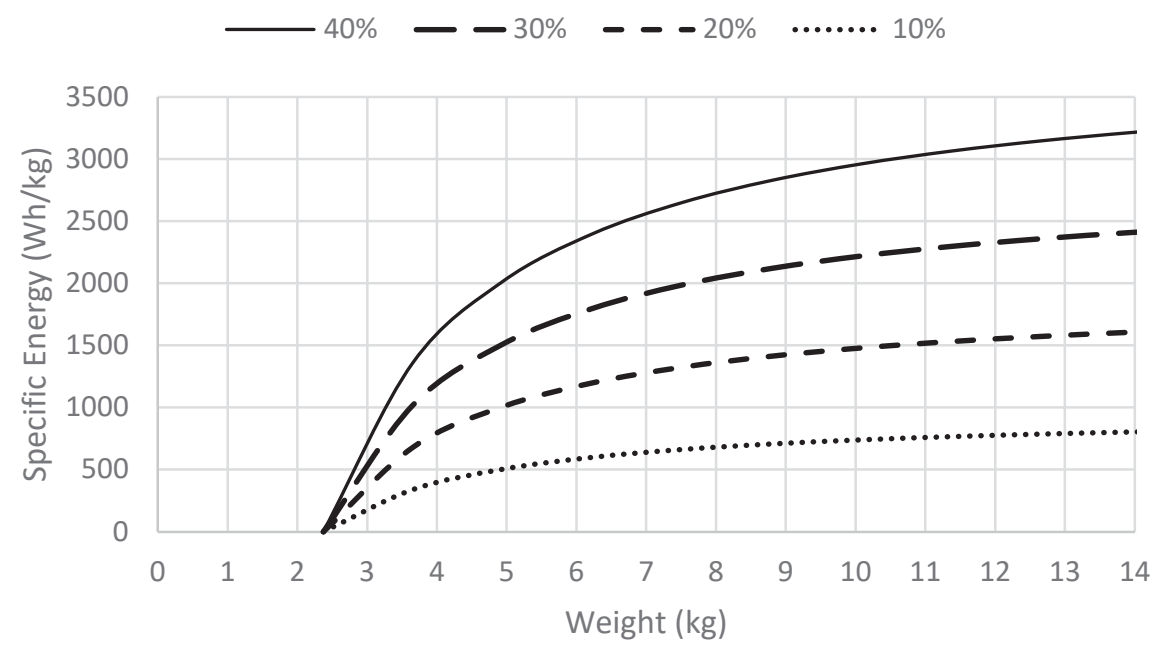

Figure 5. Comparison of fuel-to-electricity efficiency on an engines specific energy. These curves are based on the total weight of the system, and assumes specific power of $87 \mathrm{~W} / \mathrm{kg}$ and diesel fuel. Also, the weight of the container is 0.29 times the weight of the fuel.

Systems in Table 2 have specific power in a range of about $70 \mathrm{~W} / \mathrm{kg}$ to $100 \mathrm{~W} / \mathrm{kg}$, for portable power generation systems.

Figure 6 was created based on this range at intervals of $10 \mathrm{~W} / \mathrm{kg}$, to show the impact of specific power on the specific energy of the system. The difference in the specific power can be seen when specific energy equals zero, this is due to the change in specific power creating a change in the engine weight required. For example, to get $200 \mathrm{~W}$ of electricity, with a $100 \mathrm{~W} / \mathrm{kg}$ system only a 2 $\mathrm{kg}$ engine would be required. However, to produce the same power of $200 \mathrm{~W}$, a $70 \mathrm{~W} / \mathrm{kg}$ engine would weigh $2.86 \mathrm{~kg}$. This has a significant impact on the specific energy of the system when the weight of the system is reduced. The larger the total weight of 
the system, the less impact specific power has on specific energy. At a total weight of four kilograms there is about a $25 \%$ difference in specific energy for an $80 \mathrm{~W} / \mathrm{kg}$ engine and a $70 \mathrm{~W} / \mathrm{kg}$ engine. However, at $13 \mathrm{~kg}$ there is only about a $5 \%$ difference in specific energy.

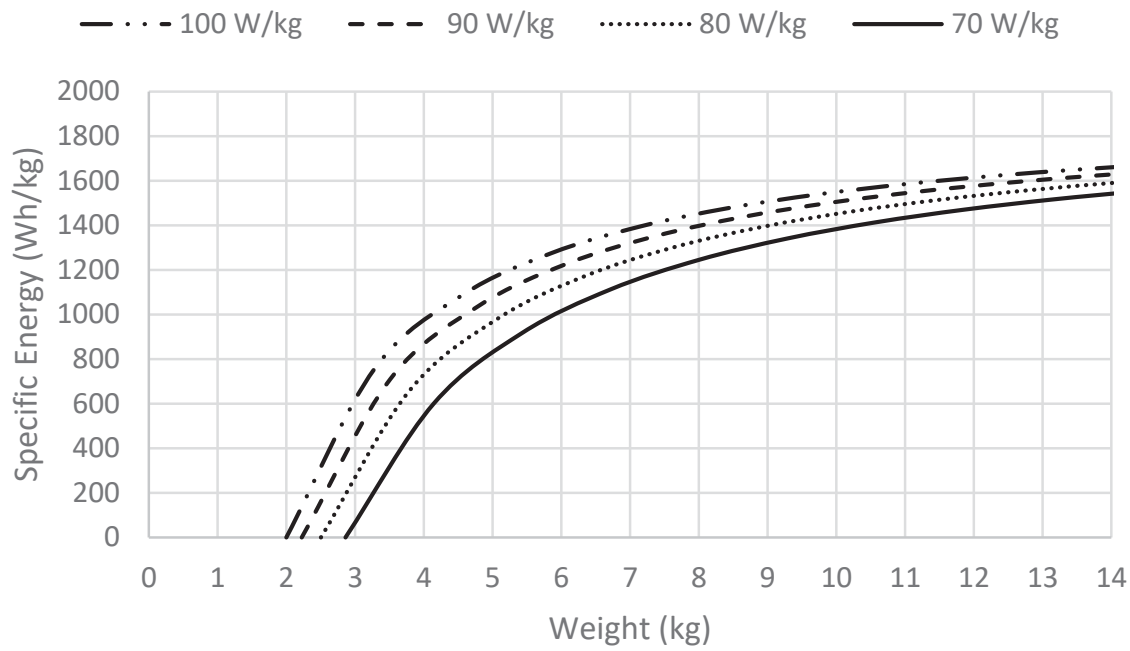

Figure 6. Comparison based on different specific power of the system. Diesel fuel and a fuel-to-electricity efficiency of $20 \%$ were assumed for this graph.

Figure 7 is a graph created to show the autonomy of operation in a portable fuel powered system based on the weight carried. The curves shown in Figure 7 compare the run time based on the efficiency of the engine. These curves were created by multiplying the specific energy by the specific power (specific power being assumed as $84 \mathrm{~W} / \mathrm{kg}$ ) and this product then multiplied by the mass of fuel at specific points to get the curves.

As seen from Figure 7, the first six kilograms define a slight parabolic curve. After six kilograms, the trend of the curves has a more linear path. The time of autonomy does not begin to be a reasonable amount for military applications until after about three kilograms. Once again, the time of autonomy is proportional to the efficiency of the system. Similar to how increasing the efficiency of the system creates a greater specific energy, it also allows for an increased time of autonomy for the system.

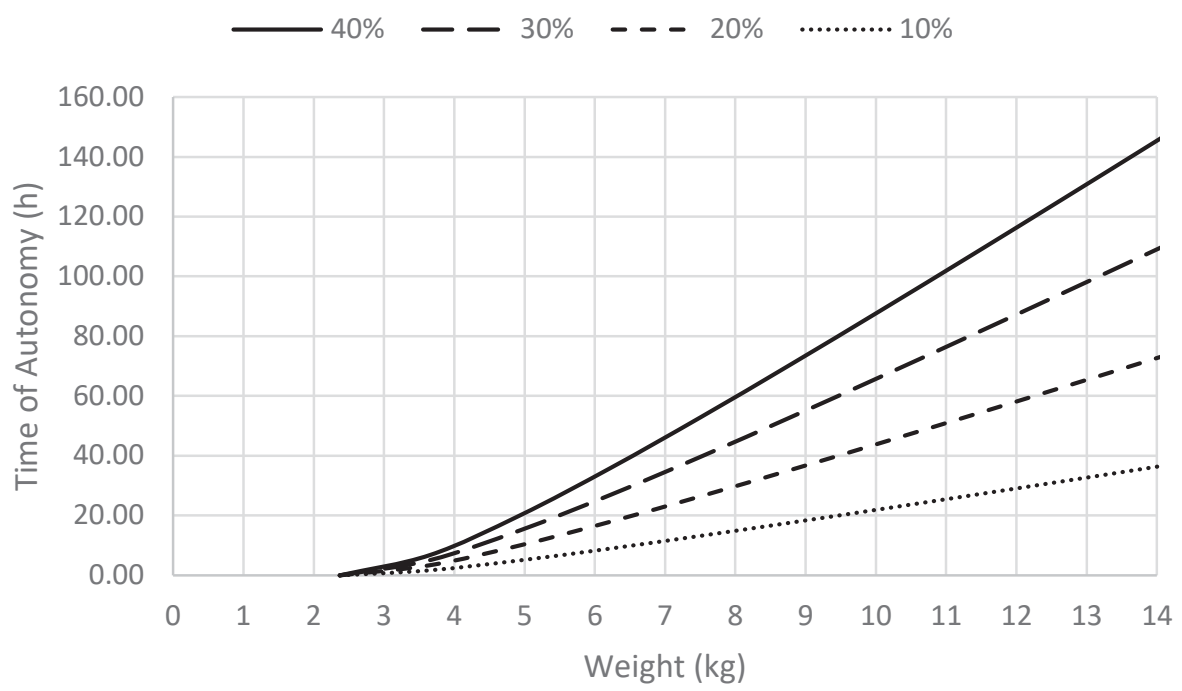

Figure 7. Time of system operation autonomy based on the weight of the entire system. Based on the efficiencies discussed in Figure 5 and a specific power of 84 $\mathrm{W} / \mathrm{kg}$.

Comparing Figure 4, 5, and 6 it is obvious that the fuel choices, the efficiency, and the specific power of an engine all influence the specific energy of a man-portable fuel power system. Occasionally the impact that those three characteristics can have on specific energy is based on weight. For instance, if there was a need to carry closer to 14 kilograms of fuel then there would be an 
impact on specific energy by changing the fuel type, than there would be by choosing an engine with a higher specific power. However, if the situation called for carrying less weight such as a total of five kilograms, then having a system with a higher specific power would have a greater impact. The specific energy of the system is proportional to the efficiency of the engine and would have a proportional impact on specific energy no matter the weight of the system. The amount of fuel that would need to be carried would be dependent on how much time the system needs to be run as shown in Figure 7.

Currently batteries are expected to allow a soldier to make it through a 72-hour mission without ever losing power. ${ }^{23}$ Currently soldiers are carrying 7.7 kilograms (17 pounds) of batteries to allow them to make it through 72-hour missions. ${ }^{24}$ In Figure 7, at a $40 \%$ efficiency and 8 kilograms, there is only a 60 -hour run time. This means that, based on the estimations made, there needs to be more advancements made for small scale engines for them to be able to replace batteries on the battlefield.

For the man-portable power generation systems to meet the energy needs that the batteries are currently fulfilling the system would weigh about 14 kilograms at a 20\% efficiency. For the best-case scenario from Figure 7, a $40 \%$ efficiency, the system would weigh about 9 kilograms to run for 72 hours at 200 Watts. For man-portable power systems to be feasible to take over batteries in military applications the systems need to be even more efficient than they currently are, along with having more specific power. Trying to reduce the size of the current systems while maintaining the current efficiencies would help increase the time of autonomy to weight ratio. Getting man-portable power generation systems to be a feasible alternative would be beneficial because the systems would not need to be recharged or operated as a one-time use system like current batteries. When the soldiers need the power they simply put fuel in the system and allow for that to power their communication systems.

\section{CONCLUSION}

There is a need for small-scale systems that generate or store electricity for use in man-portable situations, including military applications, camping, and other situations. Currently batteries are used for those man-portable situations. However, combustion engines could provide a better option based on their specific power and specific energy. Combustion engines have many different forms such as micro-turbines, micro-engines, Stirling cycles, and Organic Rankine Cycles. All must be considered when determining a system that can create a large amount of power and energy per unit of weight. External combustion engines may provide a great option because they can prevent losses and increase combustion efficiency, when compared with internal combustion engines. On the other hand, systems like Organic Rankine Cycles can operate with a lower temperature of the heat source.

Currently there is a market of internal combustion engines that are being made on a smaller scale known as Portable Generators. These portable fuel power generation systems are smaller than usual but are generally not quite small enough to meet the definition of man-portable. These systems were still studied to see if they meet the current needs of specific energy and specific power. Based on the Ragone Plots, the portable fuel power generation systems do not quite meet the standards of performance for what fuel power generation systems could meet for specific power. This in turn has kept the portable fuel power generation systems from being able to have a long enough time of autonomy to meet the needs for military use.

More research needs to be done on how to make man-portable fuel power generation systems more efficient and increase their specific power. This would allow for man-portable fuel power generation systems to be used in place of batteries for military operations. A change in the type of systems being used, such as external combustion engines, may provide the efficiency and specific power necessary to meet this demand.

\section{REFERENCES}

1. New York Independent System Operator, "Power Trends 2016 The Changing Energy Landscape," Mohawk, 2016.

2. CATRENE Working Group on Energy Autonomous Systems, "Energy Autonomous Systems: Future Trends in Devices, Technology, and Systems," CATRENE, 2009.

3. "Neutrium," 26 March 2014. [Online]. Available: https://neutrium.net/properties/specific-energy-and-energy-density-of-fuels/. [Accessed 5 October 2016].

4. U.S. Department of Energy, "Hydrogen Analysis Resource Center," January 2015. [Online]. Available: http:/ / bydrogen.pnl.gov/tools/ lower-and-higher-heating-values-fuels.

5. R. Wilson, "The Energy Collective," 9 August 2013. [Online]. Available: http:/ / wnww.theenergycollective.com/ robertwilson190/257481/why-power-density-matters. [Accessed 5 October 2016].

6. Portable Generator Manufacturers' Association, PGMA, [Online]. Available: pgmaonline.com.

7. globalindustrial.com, "Yamaha EF2000iSv2 Portable Inverter Generator, 2000 Watt 79cc OHV 4-Stroke Gas CARB Compliant," Global Equipment Company Inc., 2016. [Online]. Available:

http:// www globalindustrial.com/p/ electrical/generators/portable/yamaha-ef2000isv2-portable-inverter-generator-2000-watt-carb-compliant. [Accessed 10 October 2016].

8. Department of Defense, "Department of Defense Dictionary of Military and Associated Terms," Suffolk, 2007. 
9. Mccloskey, Bryan D. "Expanding the Ragone Plot: Pushing the Limits of Energy Storage." The Journal of Physical Chemistry Letters, vol. 6, no. 18, 2015, pp. 3592-3593., doi: 10.1021/acs.jpclett.5b01813

10. "Merriam-Webster Dictionary" (1828), Merriam-Webster. [Online]. Available: http:/ / www.merriam-webster.com/dictionary/portable.

11. K. S. J. D. James Jenden, "Energy Education," University of Calgary, [Online]. Available: bttp:// energyeducation.ca/encyclopedia/Energy_density_vs_power_density. [Accessed 18 October 2016].

12. National Academy of Sciences, "NCBI.gov," 2004. [Online]. Available: http://www.ncbi.nlm.nih.gov/books/NBK207797/.

13. Yunt, Mehmet, et al. "Designing Man-Portable Power Generation Systems for Varying Power Demand." AIChE Journal, vol. 54, no. 5, 2008, pp. 1254-1269., doi:10.1002/aic.11442

14. GoalZero, "Venture 30 Solar Recharging Kit," Goal Zero, 2016. [Online]. Available: http://www.goalzero.com/p/317/venture-30solar-recharging-kit. [Accessed 10 October 2016].

15. Pulsar Products, inc., "Pulsar 1200W 2-Stroke Generator," Pulsar Products, inc., 2016. [Online]. Available: http://pulsarproducts.com/products/pg1202s/. [Accessed 10 October 2016].

16. GeneratorSmart, "GenSmart 1000," GeneratorSmart, 2016. [Online]. Available: bttp:/ / www.generatorsmart.com/ ?product=gensmart1000. [Accessed 10 October 2016].

17. Power Magazine, "Microturbine Technology Matures," Access Intelligence, Inc., 1 November 2010. [Online]. Available: http:/ / www.powermag.com/ microturbine-technology-matures/?pagenum=1. [Accessed 12 October 2016].

18. U.S. Department of Energy, "Combined Heat and Power Technology Fact Sheet Series," U.S. Department of Energy, 2016.

19. B. Sims, "Land 125 - Power Technologies Review," Land Operations Division, Edinburgh South Australia, 2012.

20. Organ, Allan J. "Stirling Cycle Engines: Inner Workings and Design," Hoboken: Wiley, 2013. EBooks on Demand.

21. Engineering Toolbox, "engineeringtoolbox.com," [Online]. Available: http:/ / www.engineeringtoolbox.com/adiabatic-flametemperature-d_996.html. [Accessed 16 November 2016].

22. Occupational Safety and Health Administration, "Fuel Handling and Storage." [Online]. Available: http:/ / wnw.osha.gov/pls/oshaweb/owadisp.show_document?p_table=STANDARDSeop_id=10420 [Accessed 15 April 2018]

23. National Academy of Sciences, "Meeting the Energy Needs of Future Warriors," National Academies Press, Washington, D.C., 2004.

24. J. Harper, "National Defense," NDIA, October 2015. [Online]. Available: bttp:/ / mww.nationaldefensemagazine.org/archive/2015/October/Pages/TheArmyWantstoPowerUpDismountedSoldiers.aspx. [Accessed 11 December 2016].

25. A. W. Culp, Principles of Energy Conversion, Highstown: McGraw-Hill, 1991.

\section{ABOUT THE STUDENT AUTHOR}

Earl Allen obtained his B.S. in Mechanical Engineering in Spring 2017. He developed this research as part of his MENG 4395

Undergraduate Research course.

\section{PRESS SUMMARY}

Batteries are the most common source of portable electric power. However, thermally powered power generation systems offer high energy density and high power density making them candidates for further investigation as a feasible alternative. In this study, the feasibility of portable fueled power systems is investigated. 